\title{
Percutaneous atrial septal defect closure by using jugular venous access in a case with interrupted inferior vena cava
}

\author{
Nazmi Narin, Ozge Pamukcu, Ali Baykan, Mustafa Argun, Abdullah Ozyurt, Kazim Uzum \\ Paediatric Cardiology Department, Erciyes University, Kayseri, Turkey
}

Postep Kardiol Inter 2014; 10, 4 (38): 267-269

DOI: $10.5114 /$ pwki.2014.46769

\begin{abstract}
A bstract
Femoral venous approach is the classical route of percutaneous atrial septal defect (ASD) closure. But in certain circumstances alternative routes are used. In this report percutaneous ASD closure in a case with interrupted vena cava by jugular venous approach is discussed. Percutaneous closure through femoral venous route was planned in a 6-year-old girl with ASD. Because of interrupted vena cava the jugular venous route was used. Having knowledge of this anatomical variation is important for interventionalists before performing femoral venous approach. Percutaneous transjugular venous access is a feasible alternative route in paediatric population for ASD closure.
\end{abstract}

Key words: atrial septal defect, jugular venous route, paediatrics.

\section{Introduction}

The femoral venous approach is the classical route of percutaneous atrial septal defect (ASD) closure. However, in certain circumstances it is very difficult to use this route, so alternative routes were defined such as transhepatic and jugular venous approach.

In this report percutaneous ASD closure in a case with interrupted vena cava inferior by jugular venous approach is discussed.

\section{Case report}

A 6-year-old girl was referred to our clinic for heart murmur. In her physical examination a $2 / 6$ systolic murmur was heard in the left upper sternal border. Incomplete right bundle branch block was found in electrocardiography, and mild cardiomegaly was seen in telecardiography. In echocardiographic examination $16 \mathrm{~mm}$ width secundum ASD was detected. Percutaneous closure was planned, but in the angiocardiography when radiocontrast was given to the femoral vein, wide azygos vein continuation to the superior vena cava was shown. The ASD closure by femoral venous route was unsuccessful; therefore, jugular venous route was used. A catheter was first inserted to right internal jugular vein then through the superior vena cava and to the right atrium. The left atrium was entered by passing through the ASD. Balloon sizing of the ASD was then performed using a $25 \mathrm{~mm}$ sizing balloon (NuMED, Hopkinton, NY). The balloon-sized ASD diameter was $19 \mathrm{~mm}$ by fluoroscopy. $18 \mathrm{~mm}$ Amplatzer $^{\oplus}$ Septal Occluder (St. Jude Medical, Inc.) was positioned with the guidance of transesophageal echocardiography (TEE), transthoracic echocardiography (TTE), and fluoroscopy. The left atrial disc was opened far away from the mitral valve and when the right disc was planned to open, cobra movement was seen. In the second trial the device was positioned parallel to the septum. After the delivery of the device no residual shunt was detected. Also the position of device in relation to the valves and aorta was normal (Figure 1). On the same day loss of strength occurred, which was thought to be related to the haematoma in the muscles of the neck. It was completely resolved in a week. Aspirin therapy was given for 6 months. The patient had no major rhythm problems.

\section{Discussion}

Absence of intrahepatic segment of inferior vena cava, i.e. interrupted vena cava inferior with azygos continuation to superior vena cava (SVC), is a common congenital anomaly. It is usually associated with left atrial isomerism and other congenital heart diseases. Its inci-

\section{Corresponding author:}

Ozge Pamukcu MD, Paediatric Cardiology Department, Erciyes University, 38250 Kayseri, Turkey, phone: +90 5356933825,

e-mail: ozgepamukcu2002@yahoo.com

Received: 28.07.2014, accepted: 29.09.2014. 

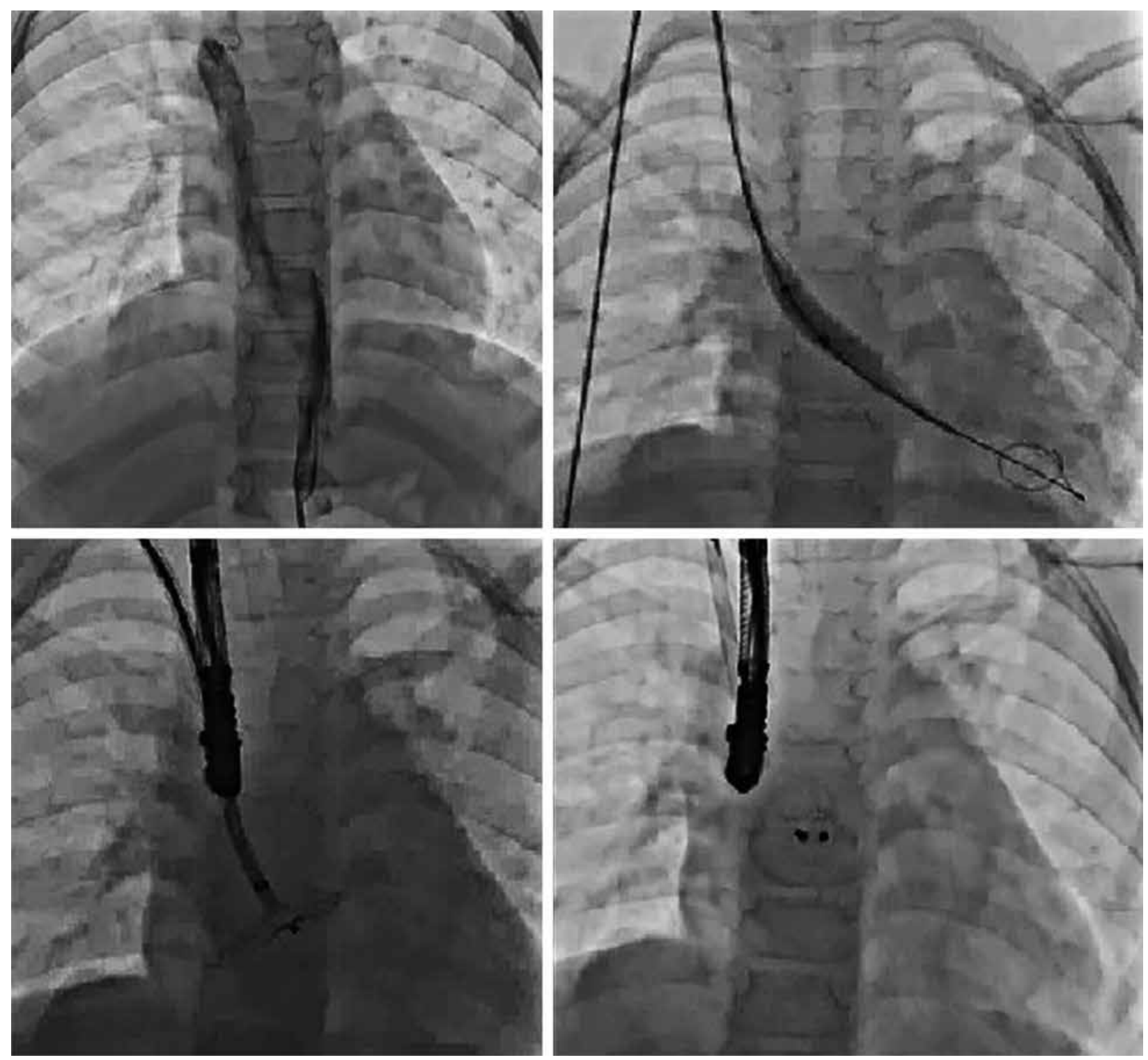

Figure 1. Percutaneous ASD closure process via transjugular route

dence in the general population is approximately $0.15 \%$. Blood from the liver drains directly to the right atrium through hepatic veins, and from the lower extremities it drains to the right atrium through azygos system. Having knowledge of this anatomical variation is important for interventionalists before performing femoral venous approach. Because percutaneous ASD closure by femoral venous route in interrupted, vena cava is very difficult to perform. It is hard to locate in pulmonary vein by femoral venous approach and deploying the device in the cases with inferior vena continuation to superior vena cava. Although there were few cases reported in the literature like 53 years old patient [1] and 2 pediatric cases [2]. In the case of interrupted vena cava, stable wire and sheath positions cannot be performed because of the anatomy of the azygos vein (abrupt 180-degree venous return and 90-degree turn across ASD) and stiffness of wire. Also, balloon sizing may not be done appropriately and is often unreliable in such cases.

Another alternative route is a transhepatic approach. It has been used for a long time for venous access in the paediatric population. It has some advantages, e.g. the large calibre of hepatic veins is optimal for sheath placement, and the inferior approach increases catheter stability. Shim et al. reported the complication rate of transhepatic approach in cardiac procedures as $<5 \%$ in a paediatric population [3]. However, this procedure must be performed with care to avoid complications because it is not completely safe. There is a risk of abdominal bleeding, peritonitis, perforation of the gall bladder, thrombosis of portal vein, liver injury, and pneumothorax in transhepatic approach.

Transjugular venous access for percutaneous ASD closure was also successfully reported in paediatric cases 
[4]. The manipulation of wires and positioning of device were also difficult. Previous case reports of closure from this route also mention difficulty in maintaining a pulmonary venous wire position and the feasibility of deploying the device from a sheath pointed toward the left ventricular (LV) inflow or left atrium (LA) appendage. Therefore transoesophageal echocardiography has an important role not only in defining the anatomy of the defect but also in tracking the wire and sheath into the LA.

There is also the risk of air embolism, but no complications have been reported in children. The risk of air embolism can be decreased by using an underwater technique of removal of dilator from the sheath. It is accepted to be safer and simpler than the transhepatic approach.

\section{Conclusions}

Percutaneous transjugular venous access is a feasible alternative route in the paediatric population for ASD closure when femoral access cannot be used.

\section{References}

1. Kashour TS, Latroche B, Elhoury ME, et al. Successful percutaneous closure of a secundum atrial septal defect through femoral approach in a patient with interrupted inferior vena cava. Congenit Heart Dis 2010; 5: 620-3.

2. Flosdorff P, Paech C, Dahnert I. Secundum atrial septal defect with interrupted inferior vena cava and azygos continuation: transfemoral closure in a 3-year old boy. Pediatr Cardiol 2013; 34: 459-61.

3. Shim D, Lloyd TR, Beekman RH III. Transhepatic therapeutic cardiac catheterization: a new option for the pediatric interventionalist. Catheter Cardiovasc Interv 1999; 47: 41-5.

4. Ozbarlas N, Kiziltas, A, Kucukosmanoglu O, et al. Transjugular approach to device closure of atrial septal defect in a child with heterotaxia and interrupted inferior vena cava. Tex Heart Inst J 2012; 39: 435-7. 